\title{
Ekoist: Journal of Econometrics and Statistics
}

Başvuru: 27.02 .2020

Revizyon Talebi: 26.04.2020

Son Revizyon Teslimi: 28.04 .2020

Kabul: 30.05 .2020

Online yayın: 19.06 .2020

\section{FED ve TCMB Politika Kararları Arasındaki Stratejik Etkileşimin Testi: Toda-Yamamoto Yaklaşımı*}

\section{Testing the Strategic Interaction Between FED and CBRT Policy Decisions: Toda-Yamamoto Approach}

\section{Metin Tetik' ${ }^{(0)}$, Görkem Kara² ${ }^{(0)}$}

\section{Öz}

Bu çalışma Federal Rezerv Bankası(FED) ve Türkiye Cumhuriyet Merkez Bankası(TCMB) politika kararları arasında stratejik bir etkileşim durumunu inceleme üzerine kurulmuştur. Bu çerçevede, çalışma TCMB' nin uyguladığı politikaların, FED' in politika kararlarından etkilenip etkilenmediğini oyun teorik bir lider-takipçi ilişkisi üzerinden analiz etmektedir. Bunun için, FED ve TCMB arasındaki etkileşim oyun teorik olarak modellenmiştir. Modelde öne sürülen hipotezler 2006M012020M12 dönemleri için Toda-Yamamoto yaklaşımını kullanılarak test edilmiştir. Bulgular, oyun teorik olarak FED’ in lider olduğu ve FED ve TCMB arasında bir lider-takipçi durumun ortaya çıktı̆ını göstermektedir.

\section{Anahtar Kelimeler \\ Para politikası kararları, Oyun teorisi, Toda-Yamamoto nedensellik testi}

\section{JEL Sınıflama Kodları}

E52, C73, C57

\begin{abstract}
This study is based on analyzing a strategic interaction situation between Federal Reserve Bank(FED) and Central Bank of the Republic of Turkey(CBRT) policy decisions. In this context, our study analyzes whether the policies implemented by the CBRT are affected by the policy decisions of the FED through a theoretical leader-follower relationship. For this, the interaction game between FED and CBRT is theoretically modeled. The hypotheses proposed in the model were tested using the Toda-Yamamoto approach for the 2006M01-2020M12 periods. Findings show that the game is theoretically the leader of the FED and a leader-follower situation arises between the FED and the CBRT.
\end{abstract}

\section{Keywords}

Monetary policy decisions, Game theory, Toda-Yamamoto causality test

JEL Classification Codes

$\mathrm{E} 52, \mathrm{C} 73, \mathrm{C} 57$

* Bu çalışma, 14 Ekim 2016 tarihinde İspanya/Barcelona'da düzenlenen 2. Uluslararası Değişen Dünya ve Sosyal Araştirma Konferansı'nda sunulan bildirinin gözden geçirilmiş ve geliştirilmiş versiyonudur.

1 Sorumlu Yazar: Metin Tetik (Dr. Öğr. Üyesi), Uşak Üniversitesi, Uygulamalı Bilimler Yüksekokulu, Uşak, Türkiye. E-posta: metin.tetik@usak.edu.tr ORCID: 0000-0003-2741-7175

2 Görkem Kara (Yüksek Lisans Öğrencisi), Uşak Üniversitesi, Ekonometri Bölümü, Uşak, Türkiye. E-posta: grk_kr_86@hotmail.com ORCID: 0000-xxxx-xxxx-xxxx

Attf: Tetik, M. ve Kara, G. (2020). FED VE TCMB Politika Kararları Arasındaki Stratejik Etkileşimin Testi: Toda-Yamamoto Yaklaşımı. EKOIST Journal of Econometrics and Statistics, 32, 35-47. https://doi.org/10.26650/ekoist.2020.32.0003 


\section{Extended Summary}

The development of financial markets in the world and the integration of these markets make the monetary policies of the countries interrelated. This study aims to analyze whether the policies implemented by the CBRT are affected by the policy decisions of the FED through the leader-follower relationship. In this framework, the research hypotheses of the study are "H1: FED policy rates do not follow CBRT policy rates" and "H2: CBRT policy rates follow FED policy rates".

In order to examine the strategic interaction between the FED and the CBRT, the strategic situation between the two policy makers was modeled theoretically. In the game, which is assumed to be uncertain, players; Represents FED (F) and CBRT (C). However, strategic interaction between players is assumed to be dynamic (extensive form games), full information and players have a pure strategy. The game between central banks is actually based on the behaviors of each central bank to maximize its own social welfare functions or minimize loss functions. With these definitions, the hypothesis of the game structure in which the FED first acted (Stackelberg Leader) was theoretically analyzed and research hypotheses were obtained.

In the study, monthly data between January 2006 and December 2019 were used to test the hypothesis of the leader-follower relationship between the FED and the CBRT. While FED policy rates are used to reflect FED decisions, CBRT policy rate is used for CBRT decisions. Both series were obtained from the IMF database. Toda and Yamamoto (1995) causality test was used to evaluate the leader-follower mechanism between the FED and CBRT policy decisions $\left(i_{t}\right.$ and $\left.r_{t}\right)$. The main reasons for using this test are that the degree of cointegration of interest (policy) rates is controversial and the Toda and Yamamoto (1995) test can also be applied when the series is not stationary.

According to the Toda-Yamamoto causality test, the null hypothesis that CBRT policy rates are not the cause for the FED policy rates cannot be rejected. On the contrary, the null hypothesis that FED policy rates are not the cause for the CBRT policy rates has been rejected. Thus, for the period of January 2006-December 2020, it was concluded that the CBRT policy rates are not the cause for the FED policy rate and the FED policy rate is the cause for the CBRT policy rate.

According to the results of the analysis, it is determined that FED takes policy decisions into consideration while determining the CBRT policy decisions. However, no evidence of the opposite situation has been encountered. This result shows that between the specified periods, the game was theoretically the FED is leader and a leader-follower situation emerged between the FED and the CBRT. 


\section{FED VE TCMB Politika Kararları Arasındaki Stratejik Etkileşimin Testi: Toda-Yamamoto Yaklaşımı}

Gelişmiş ve gelişmekte olan ülkelerdeki merkez bankalarının FED’ in politika kararlarından etkilenmesinin altında yatan temel düşüncenin, FED’ in faiz kararlarının ABD ekonomisi ve finansal piyasalar hakkında önemli sinyaller vermesi olduğu düşünülmektedir(Belke ve Gross, 2005). Bu bağlamda, TCMB politika kararlarının FED politika kararlarını izleyip izlemediği sorusunun cevabı da önem kazanmaktadır. Lider-takipçi mekanizması söz konusu olduğunda, bu yapının kurgulanması ve test edilmesi gerektiği düşünülmektedir.

Böylece bu çalışmanın literatüre katkısı şu şekilde özetlenebilir. İlk olarak çalışma, FED ve TCMB arasındaki etkileşimi oyun teorisi çerçevesinde ele almaktadır. Sonrasında ise, FED ve TCMB arasında oyun teorik olarak tasarlanan lider-takipçi yapıyı araştırmak için Hata Düzeltme Modeli’ ne (ECM) dayalı standart Granger nedensellik testi veya Granger nedensellik testi kullanan önceki çalışmaların aksine, Toda ve Yamamoto (1995) tarafindan geliştirilen Granger nedensellik yaklaşımını kullanmaktadır. Bununla birlikte, çalışmanın geri kalan kısmı şu şekilde düzenlenmiştir. Bölüm 2 ilgili literatürü sunmaktadır. Bölüm 3' te, FED ve TCMB arasındaki varsayımsal lider-takipçi yapının teorik çerçevesi ele alınmaktadır. Bölüm 4 verileri ve ampirik metodolojiyi açıklamaktadır. Bölüm 5 ampirik sonuçları vermektedir. Bölüm 6 ise çalışmamızın sonuç kısmını oluşturmaktadır.

\section{İlgili Literatür}

Literatürde yapılan çalışmalar, genellikle Avrupa Merkez Bankası(ECB) ve FED politika kararları üzerine yoğunlaşmıştır. Bu çerçevede, ECB' nin Fed' i takip etmesine ilişkin yaygın beklentiyi ortaya koyan ilk çalışma Garcia ve Cervero (2002) çalışmasıdır. Ekonomistler üzerinde yapılan bir anketle, ECB' nin, FED' in politika kararlarını takip ettiği sonucuna ulaşmışlardır. Belke, (2002a) çalışmasında ise basit istatistiksel teknikler ile ECB' nin politika kararlarında FED' i taklit ettiği sonucunun tartışmalı olduğunu iddia etmiştir. Bir başka çalışmada Ulrich (2003), ECB ve FED’ in politika davranışlarını Taylor kuralı çerçevesinde incelemiştir. Bu iki merkez bankasının Taylor tipi reaksiyon fonksiyonları arasındaki benzerlikler ve farklılıklara bakılarak bir merkez bankasının davranışının diğer bir merkez bankası üzerindeki olası etkisi analiz edilmiştir. Sonuç olarak FED' in, ECB' nin kararları üzerinde bir etkisi olduğu halde ECB' nin, FED kararlarında bir etkisi olmadığı gözlemlenmiştir. Ioannidis ve Napolitano (2003) çalışmasında ise varlık piyasaları üzerinden birbirine bağlı olan iki merkez bankasının kararlarını 3 farklı işbirliksiz oyun çerçevesinde ele almıştır. Bu çalışmada, merkez bankalarının eş anlı olarak hamle yaptıkları senaryo için Nash dengesi; FED ve ECB' nin lider-takipçi ilişkisi senaryo için ise Stackelberg dengeleri türetilmiştir. Bir diğer çalışmada Belke ve Gross (2005), FED’ in politika kararlarından etkilendiğini ancak tersi durumun geçerli olmadığını Granger 
nedensellik testleri aracılığı ile tespit etmişlerdir. Her ne kadar, ECB ve Fed arasında uzun dönemli sistematik bir asimetrik lider-takipçi ilişkisinin olduğu önerisine ampirik olarak az sayıda çalışma olsa da Eylül 2001' den sonra böyle bir asimetriyi tespit etmişlerdir. Bu çalışmada da FED ve TCMB arasındaki stratejik etkileşim, lidertakipçi oyun çerçevesinde, Ioannidis ve Napolitano (2003) çalışmasına benzer şekilde FED' in lider olduğu senaryoya odaklanılmıştır. FED ve TCMB arasındaki etkileşim oyun teorik olarak tasarlanmış, elde edilen hipotezler ampirik olarak test edilmiştir. Böylece, FED ve TCMB arasında lider takipçi ilişkisinin varlığ 1 tartışılmıştır.

\section{Oyun Teorik Çerçeve}

Belirsizliğin olmadığı varsayılan bu oyunda, oyuncuları; $\mathrm{FED}(\mathrm{F})$ ve $\mathrm{TCMB}(\mathrm{C})$ temsil etmektedir. Bununla beraber, oyuncular arasındaki stratejik etkileşim, dinamik yapıda(genişleyen biçimli), tam bilgiye dayalı ve oyuncuların pür stratejiye sahip olduğu varsayılmaktadır. FED' in stratejisini $\vec{\imath}$, TCMB' nin stratejisini $\vec{r}$, her bir merkez bankasının faydalarını $u_{f}$ ve $u_{c}$, kayıp fonksiyonlarını ise $L^{F}$ ve $L^{C}$ temsil etmektedir. Merkez bankaları arasındaki oyun aslında her bir merkez bankasının kendi sosyal refah fonksiyonlarını maksimize etme veya kayıp fonksiyonlarını minimize etme davranışları üzerine kuruludur. Buradaki kayıp fonksiyonları merkez bankalarının enflasyon, potansiyel çıktı, denge faiz hedeflerinden uzaklaşmaları üzerine kuruludur.

FED' in amaç(kayıp) fonksiyonu;

$$
L^{F}=\gamma_{\pi} \pi^{2}+\gamma_{x} x^{2}+\gamma_{i}\left(i-i^{*}\right)^{2}
$$

TCMB' nin amaç(kayıp) fonksiyonu;

$$
L^{C}=\rho_{\pi} \pi^{2}+\rho_{x} x^{2}+\rho_{i}\left(r-r^{*}\right)^{2}
$$

Denklem 1 ve 2' de temsil edilen kayıp fonksiyonları, merkez bankalarının makroekonomik dalgalanma ile mücadelesini tanımlamak için kullanılır. Denklemde $\pi$ enflasyonu, $x=\left(Y_{t}-Y_{t}^{\mathrm{n}}\right)$ çıktı açığını(cari çıktı ve potansiyel çıktı arasındaki fark), $i$ ve $r$ değişkenleri ise nominal faizleri temsil etmektedir. Bu fonksiyonlar merkez bankalarının enflasyon ve büyümedeki sapmaların(varyansların), bunlara verdikleri ağırlıklara $(\gamma$ ve $\rho)$ göre cezalandırılması üzerine kuruludur.

$\mathrm{Bu}$ çerçevede her bir oyuncunun faydası aşağıdaki gibi tanımlanabilir;

$$
\begin{aligned}
& u_{F}(\vec{i}, \vec{r})=-L^{F} \\
& u_{C}(\vec{i}, \vec{r})=-L^{C}
\end{aligned}
$$

Yukarıdaki tanımlamalarla birlikte FED' in ilk hareket ettiğini(Stackelberg Lider) düşünelim. Bu durumda teorik olarak oyunun çözümü; FED, takipçisi olan TCMB' 
nin optimal politikasını hesaba katarak en iyi tepkisini verecektir. Lider FED’ in en iyi tepkisi, takipçisi olan TCMB' nin en iyi tepkisine bağlı olacaktır. TCMB ‘ nin en iyi tepkisi ise optimal politikası olup, Nash denge çözümüdür. İki oyunculu, tam bilgili bu oyunun tasarımı aşağıdaki şekildeki gibidir.

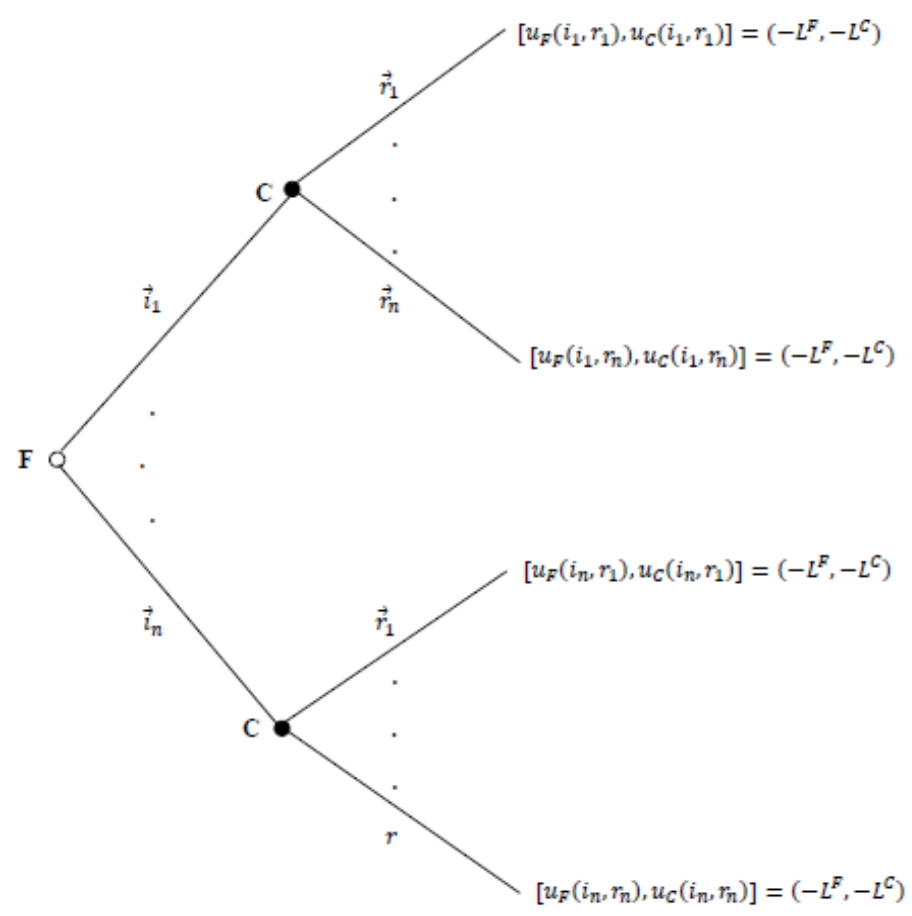

Şekil 1. FED' in stackelberg lider olduğu oyun ağacı

1. $\quad \mathrm{FED}(\mathrm{F})^{\prime}$ in $A_{F}$ olası hamleler kümesinden bir $\vec{i}$ hamlesini seçer.

2. TCMB(C) bu $\vec{r}$ hamlesini gözlemler, $A_{C}$ olası hamleler kümesinden bir $\vec{r}$ hamlesini seçer.

3. Fayda fonksiyonları(kazançlar) $u_{F}(\vec{i}, \vec{r})=-L^{F} \quad$ ve $\quad u_{C}(\vec{i}, \vec{r})=-L^{C}$ şeklindedir.

Dinamik yapıda olan bu oyunun çözümü, geriye doğru çıkarsama ile şu şekilde çözülebilir; Takipçi olan TCMB, alt oyunda hamlesini yapar ve karşısında FED' in very $\vec{i}$ hamlesini dikkate aldığı şu problem vardır;

$$
\max _{\vec{r} \in A_{C}} u_{C}(\vec{i}, \vec{r})
$$


$A_{F}$ olası hamleler kümesindeki her bir $\vec{i}$ hamlesi için TCMB' nin optimizasyon problemi $b_{c}(\vec{i})$ ile yani TCMB' nin FED' e reaksiyonu(en iyi tepkisi) ile çözülür. Sonraki aşamada, FED TCMB' nin her bir $\vec{i}$ hamlesine tepkisini öngörerek oyunun

1. bölümündeki şu problemi çözer;

$$
\max _{\vec{i} \in A_{F}} u_{F}\left(\vec{i}, b_{C}(\vec{i})\right)
$$

TCMB' nin optimizasyon problemi $\vec{i}^{N E}$ ile ifade edilen tek bir çözümü olduğu ve bu durumda $\left(\vec{i}^{N E}, b_{C}\left(\vec{i}^{N E}\right)\right)$ profili oyunun geriye doğru çıkarsama sonucu dolayısı ile alt oyun mükemmel Nash dengesi olacaktır.

$\mathrm{Bu}$ çalışmada FED ve TCMB arasında yukarıda teorik olarak değinilen bir lidertakipçi mekanizmanın varlığı incelenmektedir. Bu çerçevede çalışmanın hipotezi;

$\mathrm{H}_{1}$ : FED politika faizleri TCMB politika faizlerini takip etmez

$\mathrm{H}_{2}$ : TCMB politika faizleri FED politika faizlerini takip eder

Bu hipotezleri test etmek için belirli bir örneklemde FED ve TCMB politika kararlarını temsil eden politika oranları kullanılacaktır. FED ve TCMB politika kararları arasındaki lider-takipçi mekanizmasını analiz etmek için analiz aracını tanımlamak önemlidir. Bu bağlamda, en uygun analiz yönteminin nedensellik testlerine dayanan analiz araçları olduğu düşünülmektedir. Dolayısıyla, nedenselliğin

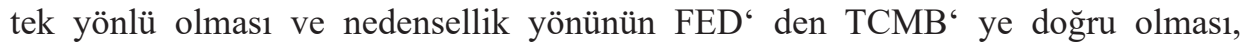
örneklem büyüklüğü (verilen örnek periyodu) ve anlamlllık düzeylerinde çalışma hipotezlerinin kabul/red edilmesini sağlayabilir.

\section{Ekonometrik Yöntem ve Veri}

\section{Ekonometrik Yöntem}

Bu çalışmada, FED ve TCMB politika kararları $\left(i_{t}\right.$ ve $\left.r_{t}\right)$ arasındaki lidertakipçi mekanizmasını değerlendirmek için, Toda ve Yamamoto (1995) nedensellik testi kullanılmıştır. Çalışmada Toda ve Yamamoto yönteminin, diğer nedensellik testleri yerine tercih edilme sebeblerinin açılanmasında fayda görülmektedir. Standart Granger (1969) nedensellik testinde, eşbütünleşik değişkenler arasında olası gecikmelerin çıkarılması nedeniyle sahte regresyon sonuçları verme olasığı bulunmaktadır. Eğer değişkenler eşbütünleşik değilse uygulanan F-testi de geçersiz olmaktadır. Zaman serileri arasındaki nedensellik testine alternatif olarak uygulanan hata düzeltme modellerinin (Engle ve Granger 1987) ve VAR hata düzeltme modellerinin (Johansen ve Juselius 1990) ise uygulamas1 görece zoruluklar içermektedir. Toda ve Phillips (1993) çalışmalarında belirttiği gibi Hata Düzeltme Modeli‘ ne dayalı (ECM) Granger nedensellik testlerinin yanlış çıkarım 
olasılığı da bulunmaktadır. Toda ve Yamamoto (1995) testi, eşbütünleşme özellikleri hakkında bilgi gerektirmez. Bu test, eşbütünleşme derecesi modelin gerçek gecikme uzunluğunu geçmediği sürece seriler durağan olmadığında ve rank koşullarını yerine getirmediğinde bile uygulanabilmektedir.

Toda ve Yamamoto yaklaşımı iki adımda gerçekleştirilebilir. İlk adımda, optimum gecikme uzunluğu ( $\mathrm{k}$ ) ve maksimum eşbütünleşme derecesi (dmax) belirlenir. VAR sisteminin gecikme yapısını belirlemek için AIC, SIC ve Hannan-Quinn gibi bilgi kriterleri kullanılır. VAR modelinin yapısı ve eşbütünleşme derecesi belirledikten sonra, toplam $\mathrm{p}=(\mathrm{k}+\mathrm{dmax})$ gecikmeli bir VAR modeli tahmin edilir.

Toda ve Yamamoto yaklaşımı, VAR (k) modelinin parametreleri üzerindeki kısıtlamaları test etmek için değiştirilmiş bir Wald (MWald) testi kullanmaktadır (Tapşın ve Karabulut, 2013, 201). MWald testi, k serbestlik derecesine sahip asimtotik bir $X^{2}$ dağılıma sahiptir. Granger nedensellik testine yönelik MWald testlerinin etkinliği Görünüşte İlişkisiz Regresyon (SUR) modelleri kullanıldığında artmaktadır(Rambaldi ve Doran, 1996). Benzer bir yaklaşımla, bu çalışmada Toda ve Yamamoto Granger nedensellik testi yapılması için, sırasıyla SUR yöntemi kullanılarak aşağıdaki gibi iki değişkenli bir VAR modeli tahmin edilmektedir.

$$
\begin{aligned}
& i_{t}^{F E D}=\alpha_{0}+\sum_{i=1}^{k+d_{\max }} \alpha_{1 i} i_{t-i}^{F E D}+\sum_{j=1}^{k+d_{\max }} \alpha_{2 j} r_{t-j}^{T C M B}+u_{t} \\
& r_{t}^{T C M B}=\beta_{0}+\sum_{i=1}^{k+d_{\max }} \beta_{1 i} r_{t-i}^{T C M B}+\sum_{j=1}^{k+d_{\max }} \beta_{2 j} i_{t-j}^{F E D}+u_{t}
\end{aligned}
$$

Denklem 3' te eğer $\alpha_{2 j}$ istatistiksel olarak anlamlı ise, TCMB politika kararları, FED' in politika kararlarının granger nedeni değildir boş hipotezi red edilir. Benzer şekilde, denklem 4' te e ğer $\beta_{2 j}$ istatistiksel olarak anlamlı ise, FED' in politika kararları TCMB politika kararlarının granger nedeni değildir boş hipotezi red edilmektedir. Böylece bu hipotezler test edilerek, oyun teorik olarak tasarladığımız FED ve TCMB arasındaki lider-takipçi ilişikisi de test edilmiş olacaktır.

\section{Veri}

Çalışmada, FED ve TCMB arasında lider-takipçi ilişkisi varlığg hipotezinin testi için Ocak 2006-Aralık 2019 dönemleri arasındaki aylık veriler kullanılmıştır. FED kararlarını yansıtması açısından FED politika oranları kullanılırken, TCMB kararları için ise TCMB politika oranı kullanılmıştır. Her iki seri IMF veri tabanından elde edilmiştir. Değişkenlerin grafiksel gösterimi Şekil 2‘ deki gibidir. 


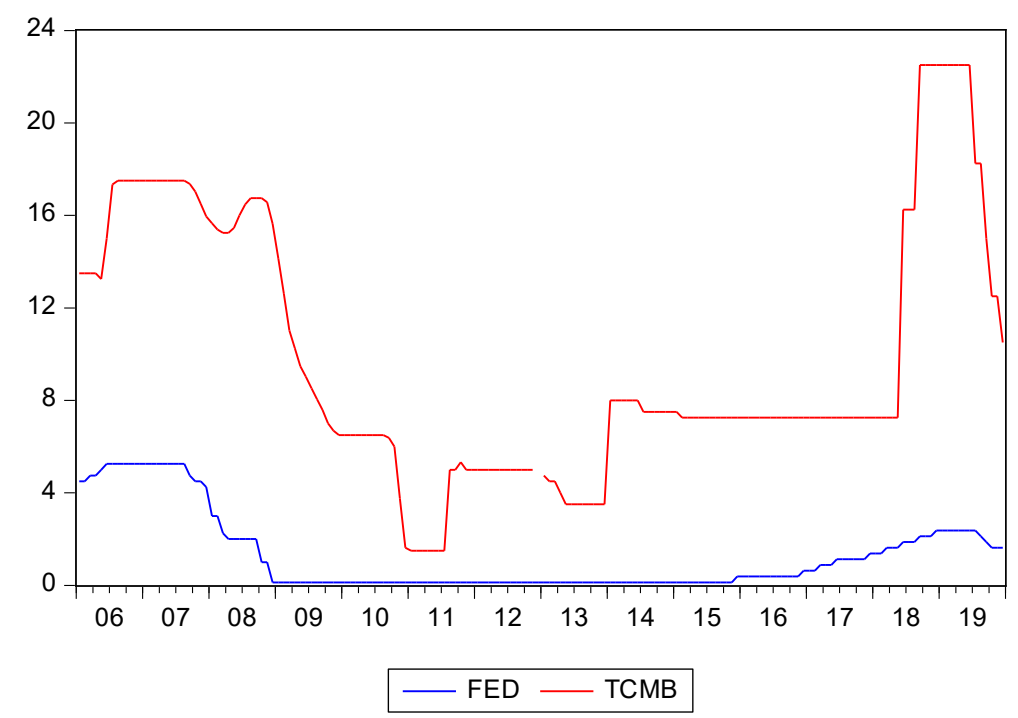

Şekil 2. FED ve TCMB Politika Faizleri

Şekil 2' ye bakıldığında FED' in, Ocak 2006' dan Ekim 2007 finansal krizinin başlangıcına kadar daraltıcı bir politika benimsediği ve politika faizini yükselttiği görülmektedir. Geriye doğru bakıldığında aslında bu politika 2002' den beri aynı şekildedir. Finansal krizin etkisi ile ABD' de büyüme ve işsizlik rakamlarının kötüleşmesi, FED' i hızlıca politika faizlerini indirmeye ve genişlemeci bir tutum sergilemeye itmiştir. 2008 yılı sonundan 2015 yılına kadar FED politika faizini sıfira yakın bir aralıkta belirlemiştir. 2015' in üçüncü çeyreği itibari ile ekonomik ve finansal göstergelerin iyileşmesi ile beraber FED’ in politika faizini artırdığı görülmektedir.

TCMB politika kararlarına bakıldığında, TCMB' nin 2002-2005 y1lında uygulamaya geçirdiği örtük enflasyon hedeflemesi ve 2006' dan itibaren yürüttügü açık enflasyon hedeflemesi ile birlikte enflasyon oranları beklentilerin altında gerçekleşmiştir. Bu durumla birlikte görülen istikrarlı büyüme rakamları, TCMB' nin politika faizlerini $\% 60$ seviyelerinden $\% 16$ seviyelerine doğru çekmesini sağlamıştır. 2008 finansal krizinin başladığ dönemlerde TCMB, politika faizlerini bir miktar yükseltse de, krizin etkilerinin Türkiye' de geçici olması ve enflasyon rakamlarının hedefler doğrultusunda ilerlemesi sonucunda politika faizlerini indirmeye devam etmiştir. 2017 yılından itibaren hızlı kur artışlarının yaşanmasının ve bunun sonuncunda enflasyon beklentilerinin yükselmesinin, TCMB' yi daraltıcı bir tutum sergilemeye ittiği görülmektedir.

Politika faiz oranlarına ilişkin çok çeşitli tanımlayıcı istatistikler Tablo 1' de verilmektedir. 
Tablo 1

Betimleyici Istatistikler

\begin{tabular}{lcc}
\hline & USA & Turkey \\
\hline Ortalama & $i_{t}$ & $r_{t}$ \\
Maksimum & 1.30 & 9.90 \\
Minimum & 5.25 & 22.50 \\
Std. Sapma & 0.13 & 1.50 \\
Çarpıklık & 1.705 & 5.692 \\
Basıklık & 1.376 & 0.710 \\
Jarque-Bera & 3.535 & 2.381 \\
Gözlem Sayısı & $54.738^{* * *}$ & $16.692 * * *$ \\
\hline
\end{tabular}

Not: Jarque-Bera normallik testidir. *** \% 1 düzeyinde istatistiksel anlamlılı̆̆

Tablo 1' e göre TCMB politika faizinin, FED politika faizinden daha oynak olduğu görülmektedir. Her iki seride de çarpıklık ve aşırı basıklık görülmektedir. Dolayıyla Jarque-Bera (JB) test istatistikleri, her iki serinin de normal dağılmadığını göstermektedir. Politika faizi serilerinin stokastik özelliklerini incelemek amacıyla standart birim kök testleri yapılmıştır. ADF (Dickey ve Fuller, 1981), PP (PhillipsPerron, 1988) ve KPSS (Kwiatkowski, Phillips, Schmidt ve Shin, 1992) test sonuçları için Tablo 2' ye bakınız.

Tablo 2

Birim Kök Testleri

\begin{tabular}{|c|c|c|c|c|c|c|c|}
\hline & & \multicolumn{2}{|c|}{ ADF Test } & \multicolumn{2}{|c|}{ PP Test } & \multicolumn{2}{|c|}{ KPSS Test } \\
\hline & & Sabit & Sabit ve Trend & Sabit & $\begin{array}{c}\text { Sabit ve } \\
\text { Trend }\end{array}$ & Sabit & Sabit ve Trend \\
\hline FED & $i_{t}$ & $-3.181^{* *}$ & -2.914 & -1.746 & -1.135 & $0.526 * *$ & $0.333 * * *$ \\
\hline TCMB & $r_{t}$ & $-2.599 *$ & -2.616 & -1.907 & -1.870 & 0.330 & $0.312 * * *$ \\
\hline \multicolumn{8}{|c|}{ Serilerin Birinci Farkı } \\
\hline FED & $\Delta i_{t}$ & -2.463 & -2.730 & $-12.164 * * *$ & $-12.146 * * *$ & $0.374 *$ & 0.081 \\
\hline TCMB & $\Delta r$ & $-4.250 * * *$ & $-4.211 * * *$ & $-11.694 * * *$ & $-11.663 * * *$ & 0.084 & 0.057 \\
\hline
\end{tabular}

Not: ADF testi için gecikme uzunluğu, Schwarz bilgi kriterine göre seçilmiștir. PP ve KPSS testleri, Newey-West bant genişliği kullanılarak Bartlett-çekirdeği temel alınarak tahmin edilmiştir. ADF ve PP testlerinin sıfır hipotezi, serinin durağan olmadı̆̆ı, KPSS testi sıfır hipotezi ise serinin durağan olduğu yönündedir. ${ }^{* *}, * *$ ve * sırasıyla $\% 1, \% 5$ ve $\% 10$ seviyelerinde istatistiksel anlamlılı̆̆ı göstermektedir.

Tablo 2' deki sonuçlar TCMB ve FED politika faizlerinin düzeyde durağan olup olmadığı hakkında net bilgi vermemektedir. Serilerin birinci farkı alındığında ise TCMB politika faizlerinin birinci farkının durağan olduğu görülürken, FED politika faizlerinin birinci farkının durağan olup olmadığı hakkında hala net bilgiye ulaşılamamaktadır. Literatürde, faiz (politika) oranlarının eşbütünleşme derecesi tartışmalıdır. Nelson ve Plosser (1982) faiz oranını durağan olmayan bir değişken olarak tanımlarken, Martin ve Milas (2013), Castro (2011), faiz oranlarının eşbütünleşme derecelerinin belirsiz olduğunu iddia ederek, durağan olarak ele almaya karar vermiştir. Bir önceki bölümde de belirtildiği gibi, Toda ve Yamamoto (1995) testi seriler durağan olmadığında da uygulanabilmektedir. Bu çerçevede, FED 
ve TCMB politika kararları arasındaki etkileşimi ampirik olarak test eden TodaYamomoto test sonuçları Tablo 3' te verilmiştir.

Tablo 3

Toda ve Yamamoto Test Sonuçlarl

\begin{tabular}{lccccc}
\hline Boş Hipotez & $\mathrm{k}$ & $\mathrm{k}+\mathrm{d}_{\max }$ & $\begin{array}{c}\text { MWald } \\
\text { İst. }\end{array}$ & p-değeri & $\begin{array}{c}\text { Nedenselliğin } \\
\text { Yönü }\end{array}$ \\
\hline$r_{t}, i_{t}^{\prime}$ 'nin Granger nedeni değildir. & 4 & $4+1=5$ & 3.365 & 0.643 & Nedensellik Yok \\
& & & & & \\
$r_{t}, i_{t}^{\prime}$ 'nin Granger nedeni değildir. & 4 & $4+1=5$ & 10.448 & $0.063^{*}$ & $i_{t} \rightarrow r_{t}$
\end{tabular}

Not: İki değişkenli VAR modeli için optimal gecikme uzunluğu (k), eşbütünleşme derecesi (dmax) ile ifade edilmiştir. Gecikme uzunluğu seçimi için Akaike Bilgi Kriterine göre karar verilmiştir . * \%10 anlamlılık düzeyini göstermektedir.

Tablo 3' teki test istatistikleri değerlendirildiğinde, Toda-Yamamoto yaklaşımına göre, Denklem 3' ün tahmin sonuçlarına dayanarak TCMB politika oranlarının FED politika oranlarının nedeni olmadığ 1 temel hipotezi reddedilememektedir. Denklem 4' ün tahminine göre ise FED politika oranlarının TCMB politika oranlarının nedeni olmadığ1 temel hipotezi reddedilmiştir. Böylece Ocak 2006-Aralık 2020 dönemi için, TCMB politika faizlerinin FED politika faizinin nedeni olmadığ 1 , FED politika faizinin ise TCMB politika faizinin nedeni olduğu sonucuna varılmıştır. Bu bulgu aynı zamanda oyun teorik çerçevede ortaya konulan çalışmanın hipotezlerini geçerli kılmaktadır. Sonuç olarak TCMB politika kararları alınırken FED politika kararlarını dikkate aldığını söyleyebiliriz. Böylece, FED ve TCMB arasında bir lider-takipçi mekanizmanın varlığından söz edilebilir.

\section{Sonuç}

Dünyada finans piyasalarının gelişmesi ve bu piyasaların birbirlerine entegre olması, ülkelerin uyguladığı para politikalarını birbirine bağlı hale getirmektedir. Dolayısı ile bu çalışmanın konusu TCMB' nin uyguladığı para politikası stratejisinin, FED' in politika kararlarını dikkate aldığ 1 fikri üzerinedir. FED' in politika kararlarının ABD ekonomisi hakkında ciddi bir sinyal olduğu düşünülürse bu durum makul gözükebilir. Dolayısı ile bu çalışmada TCMB' nin uyguladığı politikaların, FED' in politika kararlarından etkilenip etkilenmediği oyun teorik çerçevede analiz edilmiştir. TCMB ve FED arasındaki sistematik bir lider-takipçi ilişkisinin varlığını analiz etmek için öncelikle, Ocak 2006- Aralık 2020 dönemleri arasında FED ve TCMB' nin politika kararları incelenmiştir. Bu çerçevede politika kararları arasındaki ilişkinin yönünu tespit etmenin, TCMB ve FED arasındaki sistematik bir lider-takipçi ilişkisinin varlığı hakkında ipuçları verebileceği düşünülmüştür. Bunun için politika kararları arasındaki ilişki Toda-Yamomoto nedensellik yöntemi ile analiz edilmiştir. Test sonuçlarına göre, TCMB' nin politika kararlarını belirlerken, FED’ in politika kararlarını dikkate aldığı tespit edilmiştir. Ancak tersi duruma ait herhangi bir bulguya

1 Optimal gecikme uzunluğu test sonuçları Ek-Tablo-1' de görülmektedir. 
rastlanılmamıştır. Bu sonuç, belirtilen dönemler arasında oyun teorik olarak FED’ in lider olduğu ve FED ve TCMB arasında bir lider-takipçi durumun ortaya çıktığını göstermektedir.

\section{İleri Çalışmalar}

$\mathrm{Bu}$ çalışmadan elde edilen sonuçlarla birlikte, ayrı bir çalışmada da serilerde yapısal kırılmaların varlığını dikkate alan durağanlık testleri ile serilerin durağanlık özellikleri belirlenebilir. Eğer yapısal kırılmalar varsa bu kırılmalar modellenerek ayrı bir nedensellik yaklaşımı ile çalışmanın iktisadi hipotezi sınanabilir.

\footnotetext{
Hakem Değerlendirmesi: Dış bağımsız.

Çıkar Çatışması: Yazar çıkar çatışması bildirmemiştir.

Finansal Destek: Yazar bu çalışma için finansal destek almadığını beyan etmiştir.

Peer-review: Externally peer-reviewed.

Conflict of Interest: The author has no conflict of interest to declare.

Grant Support: The author declared that this study has received no financial support.
}

\section{Kaynakça/References}

Belke, A. (2002). Does the ECB Follow the FED? (No. 211/2002). Department of Economics, University of Hohenheim, Germany.

Belke, A., \& Gros, D. (2005). Asymmetries in transatlantic monetary policy-making: Does the ECB follow the fed? JCMS: Journal of Common Market Studies, 43(5), 921-946.

Castro, V. (2011). The impact of the European Union fiscal rules on economic growth. Journal of Macroeconomics, 33(2), 313-326.

Engle, R. F., \& Granger, C. W. (1987). Co-integration and error correction: representation, estimation, and testing. Econometrica: journal of the Econometric Society, 251-276.

Garcia-Cervero, S. (2002). Is the Fed really leading the way. Deutsche Bank Europe Weekly, 22, 8-10.

Granger, C. W. (1969). Investigating causal relations by econometric models and cross-spectral methods. Econometrica: Journal of the Econometric Society, 424-438.

Ioannidis, C., \& Napolitano, O. (2003). Optimal Monetary Policy and the Asset Market: A Noncooperative Game.

Kwiatkowski, D., Phillips, P.C., Schmidt, P. and Shin, Y. (1992). Testing the null hypothesis of stationarity against the alternative of a unit root: How sure are we that economic time series have a unit root? Journal of Econometrics, 54(1), 159-178.

Nelson, C. R., \& Plosser, C. R. (1982). Trends and random walks in macroeconmic time series: some evidence and implications. Journal of monetary economics, 10(2), 139-162.

Martin, C., \& Milas, C. (2013). Financial crises and monetary policy: Evidence from the UK. Journal of Financial Stability, 9(4), 654-661.

Phillips, P. C., \& Perron, P. (1988). Testing for a unit root in time series regression. Biometrika, $75(2), 335-346$. 
Rambaldi, A. N., \& Doran, H. E. (1996). Testing for granger non-casuality in cointegrated systems made easy. Department of Econometrics, University of New England.

Tapşın, G., \& Karabulut, A. T. (2013). Reel döviz Kuru, ithalat ve ihracat arasındaki nedensellik İlişkisi: Türkiye örneği. Akdeniz Üniversitesi İktisadi ve İdari Bilimler Fakültesi Dergisi, 13(26), 189-204

Ulrich, K. (2003): A Comparison Between the Fed and the ECB: Taylor Rules, ZEW Discussion Paper No. 03-19, Centre for European Economic Research, Mannheim.

Toda, H. Y., \& Phillips, P. C. (1993). Vector autoregressions and causality. Econometrica: Journal of the Econometric Society, 1367-1393.

Toda, H. Y., \& Yamamoto, T. (1995). Statistical inference in vector autoregressions with possibly integrated processes. Journal of econometrics, 66(1-2), 225-250. 
Ek Tablo-1

VAR Gecikme Uzunluğu Belirleme Kriterleri

\begin{tabular}{ccccccc} 
Gecikme & LogL & LR & FPE & AIC & SC & HQ \\
\hline 0 & -732.8525 & NA & 44.97981 & 9.481968 & 9.521238 & 9.497918 \\
1 & -195.2665 & 1054.362 & 0.046016 & 2.596987 & 2.714797 & 2.644839 \\
2 & -192.0595 & 6.207170 & 0.046491 & 2.607219 & 2.803569 & 2.686972 \\
3 & -179.8949 & 23.23032 & 0.041846 & 2.501870 & 2.776760 & 2.613524 \\
4 & -163.8230 & 30.27754 & $0.035815^{*}$ & $2.346103 *$ & $2.699533^{*}$ & $2.489658^{*}$ \\
5 & -163.4279 & 0.734062 & 0.037528 & 2.392618 & 2.824588 & 2.568075 \\
6 & -161.0915 & 4.280842 & 0.038355 & 2.414084 & 2.924594 & 2.621442 \\
7 & -158.9115 & 3.938020 & 0.039283 & 2.437568 & 3.026618 & 2.676827 \\
8 & -152.2733 & 11.82045 & 0.037989 & 2.403526 & 3.071116 & 2.674686 \\
9 & -151.3904 & 1.549236 & 0.039576 & 2.443747 & 3.189877 & 2.746809 \\
10 & -142.4815 & $15.40388 *$ & 0.037180 & 2.380406 & 3.205076 & 2.715368 \\
11 & -141.4826 & 1.701256 & 0.038689 & 2.419130 & 3.322341 & 2.785994 \\
12 & -139.2783 & 3.697555 & 0.039646 & 2.442301 & 3.424051 & 2.841065 \\
\hline
\end{tabular}

* LR kriteri tarafından seçilen gecikme sırasını gösterir. LR: Sıralı modifiye LR test istatistiği (\% 5 seviyesinde) FPE: Son tahmin hatas1, AIC: Akaike bilgi kriteri SC: Schwarz bilgi kriteri HQ: Hannan-Quinn bilgi kriteri 
